Original Article

\title{
BIOCHEMICAL AND HISTOPATHOLOGICAL CHANGES OF TRADITIONAL SIDDHA FORMULATION ON CCL4 INDUCED LIVER FIBROSIS IN RATS
}

\author{
DIWAKAR MANICKAMa', SRI KAMATCHI PRIYA RAMAMOORTHYb, B. SANTHOSH KUMARc, \\ SAMU SUBRAMANIAM ${ }^{*}$, SHYAMA SUBRAMANIAMe
}

\begin{abstract}
a,b,cDepartment of Biochemistry, Regenix Super Speciality Laboratories, Affiliated to University of Madras, Chennai, Tamilnadu, India, $\mathrm{d}^{*}$ Lab Director, Head of the Department, Department of Biochemistry, Regenix Super Speciality Laboratories, Chennai, Tamilnadu, India, eConsultant, Lab Services, Apollo Hospital, Chennai, Tamilnadu, India

Email: subramaniam@regenix.in

Received: 05 Apr 2017 Revised and Accepted: 19 May 2017
\end{abstract}

\begin{abstract}
Objective: The main objective of this study was to evaluate the therapeutic activity of traditional Siddha formulation (TSF) on $\mathrm{CCl}_{4}$ induced liver fibrosis in rats.

Methods: Plant materials were collected, shade dried and mixed in equal proportion. This mixture was used for the extraction process (kasayam). Twenty four male Wistar albino rats were randomly divided into four groups of six rats each. The normal control group was allowed free access to food and water. The drug control group was allowed to the daily intragastric administration of TSF dosage $400 \mathrm{mg} / \mathrm{kg}$ body weight/day. Liver damage was performed in the remaining two groups with an intraperitoneal injection of a $1.0 \mathrm{ml} / \mathrm{kg}$ body weight $\mathrm{CCl}_{4}$ and olive oil $(2: 3 \mathrm{v} / \mathrm{v})$ mixture, weekly twice for $8 \mathrm{w}$. All rats, with the exception of the injury model group, were intragastrically administered TSF dosage $400 \mathrm{mg} / \mathrm{kg}$ body weight/day from $5^{\text {th }}$ week to end of the experiment of $\mathrm{CCl}_{4}$ intoxicated rats. The serum levels of Alanine Transaminase (ALT), Aspartate Transaminase (AST), Alkaline Phosphatase (ALP), Lactate Dehydrogenase (LDH), Ү-Glutamyl Transferase (Y-GT), Albumin (ALB), Total Protein (TP) and Total Bilirubin (TB) and Hydroxyproline (HYP) in the rat livers were measured. Histopathological changes in the liver were assessed for each group using hematoxylin and eosin and Masson trichrome staining procedures.
\end{abstract}

Results: At the end of the 8-week experimental period, histopathological examination and Masson trichrome staining demonstrated that TSF could attenuate inflammation, necrosis and reduce the score of liver fibrosis. Similarly, we found that the TSF administration significantly decreased the levels of biomarkers AST $(136.25 \pm 3.88, \mathrm{p}<0.01)$, ALT $(64.81 \pm 4.68, \mathrm{p}<0.01)$, ALP $(132.21 \pm 8.30, \mathrm{p}<0.01)$, LDH $(1451.66 \pm 49.56, \mathrm{p}<0.01), \mathrm{TB}$ $(0.87 \pm 0.04, p<0.01), \Upsilon$-GT $(12.81 \pm 1.74, p<0.01)$, HYP $(8.05 \pm 0.76, p<0.01)$ and significantly increased ALB $(3.73 \pm 0.24, p<0.01), T P(5.76 \pm 0.15$, $\mathrm{p}<0.01)$, in associated with hepatic damage compared with $\mathrm{CCl}_{4}$ intoxicated group.

Conclusion: TSF attenuates $\mathrm{CCl}_{4}$ intoxicated hepatic fibrosis in Wistar rats, which may be related to essential phytochemical ingredients rich in this formulation. These therapeutic activities were in the form of improving the serum biochemical parameters and a histopathological picture of the liver.

Keywords: Traditional Siddha formulation, Liver fibrosis, CCl4 and Vaithiyars

(C) 2017 The Authors. Published by Innovare Academic Sciences Pvt Ltd. This is an open access article under the CC BY license (http://creativecommons.org/licenses/by/4.0/) DOI: http://dx.doi.org/10.22159/ijpps.2017v9i7.18942

\section{INTRODUCTION}

Liver fibrosis is the scarring process, characterized by the loss of hepatocytes destruction, hepatic architecture, proliferation of hepatic fibroblast [1] to chronic injury, including alcohol, chronic viral hepatitis, nonalcoholic fatty liver diseases and drug exposure [2], results imbalance secretion and degrading of extracellular matrix including collagen, polysaccharide and glycoprotein which distorts liver architecture [3]. Advanced liver fibrosis leads to cirrhosis, liver failure and portal hypertension [4].

Carbon tetrachloride is a widely used potent hepatotoxin for induction of hepatocellular damage involving enhanced inflammatory process, recruitment of inflammatory cells [5], hepatocyte apoptosis [6], increase oxidative stress [7], oxidative stress plays important role in the development of chronic and degenerative diseases [8]. $\mathrm{CCl}_{4}$ induced liver fibrosis model similar to all important properties of liver diseases from chronic hepatitis to liver fibrosis in human [9]. The toxicity of $\mathrm{CCl}_{4}$ attributed to the production of free radical and reactive oxygen species during metabolism [10]. Free radicals are highly unstable molecules have electron easily react with various organic compounds such as lipids, protein, carbohydrates and DNA in cells and tissues. This ultimately results in membrane damage, lipid peroxidation and fragmentation lead to cell death [11].

Three traditional systems of medicine are practiced in India, they are Siddha, Ayurveda and Unani. Siddha system of healing and medication is more popular in south India used for many chronic ailments [12].
Siddha medicine is practiced mainly by institutionally trained and noninstitutionally trained practitioner. Non-institutionally Siddha practitioner named as Siddha Vaithiyars got knowledge through hereditary family training or teachers (Aasaan). A Large number of Siddha formulation includes plant, herbomineral, animal kingdom based medicine passed among the family member of the practitioner and rarely to a lot of cures and formulations are secret [13]. Traditional formulation is a polyherbal Siddha formulation consists of seven botanicals used by the traditional Siddha medicine practice for liver disease. Qualitative analysis of TSF showed the presence of various beneficial phytochemicals like flavonoids, alkaloids, terpenoids, saponin, steroids and rich in polyphenols [14]. The aim of the present study was to observe and document the therapeutic activity of TSF on liver fibrosis induced by $\mathrm{CCl}_{4}$ in Wistar rats.

\section{MATERIALS AND METHODS}

Chemicals

$\mathrm{CCl}_{4}$ were purchased from Sigma-Aldrich Chemicals, USA. Trichloroacetic acid, hydroxyproline, $\mathrm{HCl}$, chloramine- $\mathrm{T}$ and $\mathrm{p}$ dimethylamino benzaldehyde were purchased from Merck. All biochemical analysis kits were purchased from Bio System Diagnostics Pvt Ltd. All other chemicals were of the highest purity and analytical grade. $\mathrm{CCl}_{4}$ was diluted 2:3 ratio with olive oil.

\section{Drug preparation and dose determination}

TSF is a combination of seven botanicals include Sphagneticola calendulacea whole plant, Phyllanthus amarus whole plant, Terminalia 
chebula pericarp, Terminalia belerica fruit, Emblica officinalis fruit, Curcuma longa rhizome and Cuminum cyminum fruit. The seven ingredients were collected from fields and country drug shops in Thiruvallur district, Tamil Nadu, India and submitted to the Siddha central research institute, Chennai, India, for botanicals and drug authentication. All the ingredients were washed, shade dried, then coarsely powdered separately and mixed in equal proportion to get a traditional Siddha formulation mixture. Preparation of water extract (kasayam) from TSF mixture described previously [14], the selection of plants based on the traditional Siddha medicine practice and also every plant has hepatoprotective referred from the Siddha materia medica written by vaithya Ratnam K. S. Murugesa mudaliaar [15]. The dose of TSF used (400 mg/kg body weight/day) was decided based upon a dose-dependent study. Acute toxicity studies showed no mortality and sub-acute toxicity studies showed no significant changes in biochemical parameters, haematological, and histopathological studies. Based on these studies, we carried out a dose-dependent study at doses of $200,400,600 \mathrm{mg} / \mathrm{kg}$ body weight/day. The results of this study revealed that $400 \mathrm{mg} / \mathrm{kg}$ body weight as evidenced by histopathological observations, a significant $(P<0.05)$ increase in body weight and a significant $(P<0.05)$ reduction in the levels of marker enzymes in serum and liver (Unpublished data). The duration of treatment is $28 \mathrm{~d}$ (Arai mandalam) which is used by Siddha (a traditional Indian system of medicine) physicians for treating chronic liver disease patients utilizing TSF Thus the optimum dose of TSF was found to be $400 \mathrm{mg} / \mathrm{kg}$ body weight/day for $28 \mathrm{~d}$, and this dose was used for all the subsequent experiments.

\section{Animals}

Institutional animal ethical committee (IAEC) at Saveetha University approved the experimental protocol of this study (SU/BRULAC/ RD/019/2014). Male albino Wistar rats (150-180 g) were obtained from the king Institute of preventive medicine, Chennai, India. All rats were housed in polyethene cages under controlled laboratory condition of temperature $20-22^{\circ} \mathrm{C}$ with $12 \mathrm{~h}$ dark and light cycle and provide with standard rat pellet and water, ad libitum.

\section{Experimental design}

After one week acclimatization period rats were randomly assigned into four groups ( $\mathrm{n}=6$ per group). Group 1 (Normal control) was allowed free access to food and water for eight weeks. Group 2 (Model group) received intra peritoneal injections of $1 \mathrm{ml} / \mathrm{kg} \mathrm{CCl} 4$ and olive oil $(2: 3 \mathrm{v} / \mathrm{v})$ mixture twice a week for eight weeks as described by Gy li et al. [16]. Group 3 (Therapeutic model) received CCl4 as per group 2 followed by TSF orally $400 \mathrm{mg} / \mathrm{kg}$ body weight daily from $5^{\text {th }}$ week to end of the experiment. Group 4 (Drug control) rats received TSF 400 $\mathrm{mg} / \mathrm{kg}$ body weight daily for eight weeks. At the end of the experimental period, all the rats were anesthetized by ketamine hydrochloride intravenously $30 \mathrm{mg} / \mathrm{kg}$ body weight. A sample of liver tissue and blood were collected for further analysis.

\section{Determination of serum biomarker for liver damage}

Serum level of Alanine Transaminase, Aspartate Transaminase, Alkaline Phosphatase, Lactate Hydrogenase, $\Upsilon$-Glutamyl Transferase,
Albumin, Total Protein and Total Bilirubin were measured using commercial kit available (BioSystems Diagnostics Pvt Ltd.) according to manufacturer's instruction.

\section{Hydroxyproline content in liver tissue}

$100 \mathrm{mg}$ of liver tissue was taken for hydroxyproline determination according to Woessner, J. F 1961. $100 \mathrm{mg}$ of tissue was homogenised with $100 \mathrm{ml}$ of $5 \%$ trichloroacetic acid and kept at $90^{\circ} \mathrm{C}$ for $30 \mathrm{~min}$ to extract protein, DNA and collagen. The solution was filtered and the filtrate was used for estimation. Aliquots of the $5 \%$ trichloroacetic acid extract were hydrolyzed by adding hydrochloric acid to a final concentration of $6 \mathrm{~N}$ in sealed tubes for $3 \mathrm{~h}$ at $130^{\circ} \mathrm{C}$. After hydrolysis the sample was evaporated to dryness the residue was dissolved in water and made up to a known volume. Hydroxyproline oxidation was initiated by adding $1.0 \mathrm{ml}$ chloramines-T to each tube, the tube content was mixed by shaking a few times and allowed to stand for $20 \mathrm{~min}$ at room temperature. The chloramines-T was then destroyed by adding 1.0 $\mathrm{ml}$ Perchloric acid to each tube. The content was mixed and allowed to stand for $5 \mathrm{~min}$. Finally $1.0 \mathrm{ml}$ p-dimethyl amino benzaldehyde solution was added and the mixture was shaken. The tubes were placed in a water bath for $20 \mathrm{~min}$, then cooled with tap water for $5 \mathrm{~min}$. The color developed was read on a Chemito UV spectrophotometer at $557 \mathrm{~nm}$.

\section{Histological examination}

The liver specimen was fixed in $10 \%$ formalin solution, dehydrated with graded alcohol, embedded in paraffin, cut 5-micrometer thickness section and stained with hematoxylin and eosin. Histopathological changes of each liver slide were examined under a light microscope (Labomed). For collagen deposition, fixed section was stained with Masson trichrome using a standard protocol.

\section{Statistical analysis}

The data were expressed as the mean \pm SD for the six rats in each group. Statistically significant differences between the groups were calculated using SPSS. The value of $\mathrm{p}<0.05$ was considered to the statically significant.

\section{RESULTS}

\section{Effect of TSF on body weight}

Alteration in the body weight and liver weight in the control and $\mathrm{CCl}_{4}$ intoxicated groups monitored during the progression of $\mathrm{CCl}_{4}$ induced liver fibrosis. Body weight and liver weight of the rats significantly decreased $(\mathrm{p}<0.01)$ in $\mathrm{CCl}_{4}$ treated rats, and significantly increased $(\mathrm{p}<0.01)$ in control and $\mathrm{CCl}_{4}+\mathrm{TSF}$ treated group shown in table 1

\section{Effect of TSF on liver function}

The curative effect of TSF on biochemical markers of liver fibrosis in $\mathrm{CCl} 4$ induced rates shown in table 1 . The rats treated with $\mathrm{CCl}_{4}$ had significantly $(\mathrm{p}<0.01)$ elevated levels of serum AST, ALT, ALP, LDH, YGT, Total bilirubin and significantly reduced $(\mathrm{p}<0.01)$ the level of total protein and albumin compare to the normal group. However, treatment with TSF after $\mathrm{CCl}_{4}$ intoxication significantly $(\mathrm{p}<0.01)$ reduced the elevated level of AST, ALT, ALP, LDH, YGT and Total bilirubin to near normal level and significantly increased $(\mathrm{p}<0.01)$ the total protein and albumin to normal level shown in table 1

Table 1: Effect of TSF on liver function parameters in $\mathrm{CCl}_{4}$ induced rats

\begin{tabular}{llll}
\hline Parameter & Control group & Induced group & Therapeutic group \\
\hline Body Weight & $243.33 \pm 8.16$ & $169.16 \pm 5.84^{\mathrm{a}^{* *}}$ & $211.66 \pm 7.52^{\mathrm{b}^{* *}}$ \\
Liver Weight & $7.73 \pm 0.16$ & $5.83 \pm 0.25^{\mathrm{a}^{* *}}$ & $6.81 \pm 0.22^{\mathrm{b}^{* *}}$ \\
ALT & $52.96 \pm 0.95$ & $188.30 \pm 8.24^{\mathrm{a}^{* *}}$ & $64.81 \pm 4.68^{\mathrm{b}^{* *}}$ \\
AST & $117.86 \pm 4.13$ & $264.93 \pm 5.46^{\mathrm{a}^{* *}}$ & $136.25 \pm 3.88^{\mathrm{b}^{* *}}$ \\
ALP & $111.63 \pm 7.07$ & $297.76 \pm 4.6 \mathrm{a}^{\mathrm{a}^{* *}}$ & $132.21 \pm 8.30^{\mathrm{b}^{* *}}$ \\
Total Protein & $6.65 \pm 0.35$ & $4.95 \pm 0.16^{\mathrm{a}^{* *}}$ & $5.76 \pm 0.15^{\mathrm{b}^{* *}}$ \\
Albumin & $4.13 \pm 0.13$ & $2.90 \pm 0.10^{\mathrm{a}^{* *}}$ & $3.73 \pm 0.24 \mathrm{~b}^{\mathrm{b}^{* *}}$ \\
Total Bilirubin & $0.50 \pm 0.04$ & $1.31 \pm 0.07^{\mathrm{a}^{* *}}$ & $0.87 \pm 0.04^{\mathrm{b}^{* *}}$ \\
Y-GT & $5.95 \pm 0.38$ & $26.63 \pm 3.41^{\mathrm{a}^{* *}}$ & $118.45 \pm 5.65$ \\
HydroxyProline & $3.46 \pm 0.16$ & $17.76 \pm 0.55^{\mathrm{a}^{* *}}$ & $8.85 \pm 1.74 \mathrm{~b}^{* *}$ \\
LDH & $1158.66 \pm 50.85$ & $2061 \pm 74.77^{\mathrm{a}^{* *}}$ & $16.05 \pm 0.76^{\mathrm{b}^{* *}}$ \\
\hline
\end{tabular}

Values are expressed as mean \pm SD. $(n=6)$. Statistical significance at $\mathrm{p}<0.05$. Comparisons are made with 'a' control group and ' $\mathrm{b}$ ' induced group. ${ }^{*} \mathrm{p}<$ $0.05,{ }^{* *} \mathrm{p}<0.01$. Rat body weight and liver weight are expressed in grams. AST, ALT, ALP, LDH and $\gamma$-GT activities are expressed as IU/l. Total protein and albumin are expressed in $\mathrm{g} / \mathrm{dl}$, total bilirubin are expressed in $\mathrm{mg} / \mathrm{dl}$ and hydroxyproline are expressed in the $\mu \mathrm{g} / \mathrm{g}$ tissue 


\section{Effect of TSF on hepatic hydroxyproline content}

Hepatic hydroxyproline content was significantly $(\mathrm{p}<0.01)$ increased in the $\mathrm{CCl}_{4}$ group compared with the control group. Compared with the $\mathrm{CCl}_{4}$ group, the levels of hydroxyproline were significantly $(\mathrm{p}<0.01)$ decreased in the treatment group shown in table 1.

\section{Effect of TSF on histopathological examination}

Control rats showed the normal histological appearance (fig. 1A) whereas $\mathrm{CCl}_{4}$ induced group showed many pathological changes include infiltration of lymphocyte, portal inflammation (fig. 1D), hepatocyte ballooning and hepatocyte feathery degeneration changes in both portal tract (fig. 1B) and around the central vein (fig. 1C), whereas Treatment with TSF groups displayed completely reversed the pathological changes of liver extensively when compare to $\mathrm{CCl}_{4}$ groups and almost similar to normal group (fig. 1F).
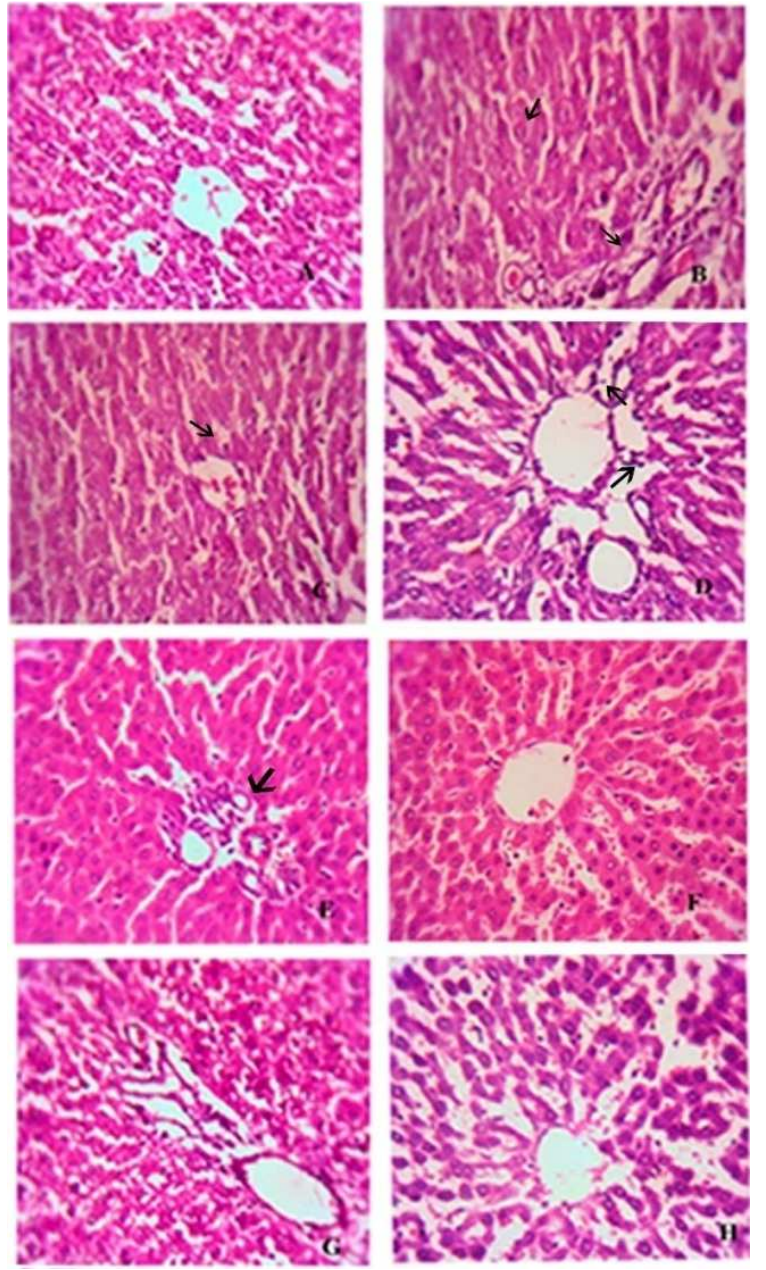

Fig. 1: Microscopic examination of the liver in control and experimental groups determined by hematoxylin and eosin (original magnification 400x liver section in rats) staining is presented in A-H; (A): Control; (B): $\mathrm{CCl}_{4}$ control liver showing degenerative changes of hepatocyte in the periportal region (arrow); (C): $\mathrm{CCl}_{4}$ intoxicated liver showing hepatocyte

degeneration around central vein (arrow mark); (D): Inflammatory cell infiltration in periportal region; (E): $\mathrm{CCl}_{4+}$ TSF treated liver showing few inflammatory cell inflammation (Arrow mark); (F):

$\mathrm{CCl}_{4}+\mathrm{TSF}$ treated liver showing a normal architecture with granulated cytoplasm; (G): TSF treated significantly ameliorated these pathological changes and exhibited normal architecture; $(\mathrm{H})$ : TSF control group showing the normal architecture of liver cells

TSF treatment decreases the infiltration of the inflammatory cell shown in (fig. 1E). The group treated with TSF showed a less destruction of the liver architecture without fibrosis shown in (fig. 1G). Masson trichrome staining with liver section exhibited collagen deposition increased in $\mathrm{CCl}_{4}$ group compared to control group shown in (fig. 2B). Treatment with TSF resulted in a reduced the degree of fibrosis appearance shown in (fig. 2C)
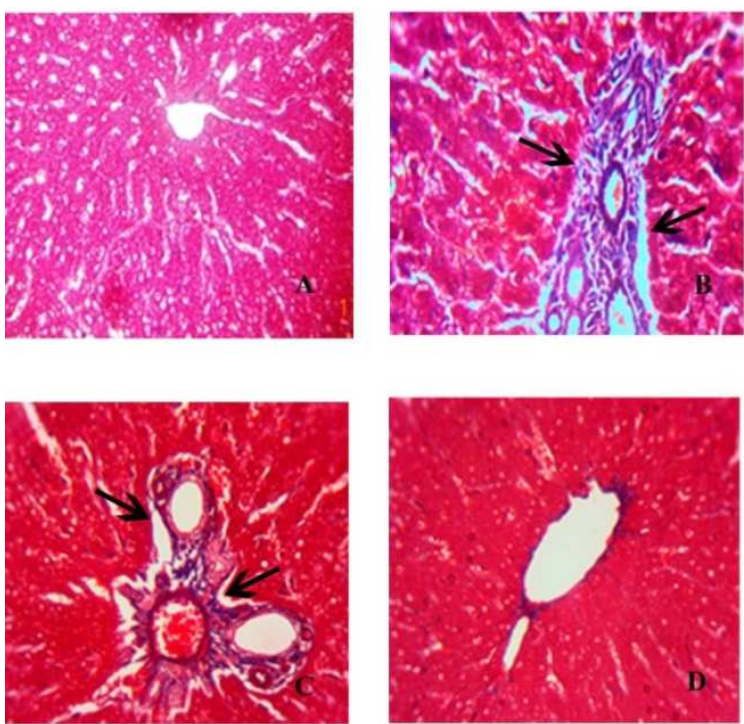

Fig. 2: Photomicrographs of rat liver (Masson trichrome stain). (A) Normal control. (B) CCl4 group showing massive collagen deposition in portal areas. (C) Therapeutic group showing an obvious reduction in collagen deposition in the portal area. (D)

TSF control group showing normal histology. Collagen deposition stained with trichrome staining (blue colour)

\section{DISCUSSION}

In the present study, TSF exhibited a curative effect, as demonstrated by a significant reduction in ALT and AST level and also confirmed by histopathological changes in the liver of rats treated with $\mathrm{CCl}_{4}$ induced liver fibrosis. Hepatotoxicity of $\mathrm{CCl} 4$ is attributed to free radical generation during its metabolism in the endoplasmic reticulum. The free radical thus formed can attack lipid on the membrane of the endoplasmic reticulum to elicit lipid peroxidation [17], disturbs $\mathrm{ca}^{2+}$ homeostasis which finally result in cell death. This leads to hepatocyte damage and release of intracellular enzymes like AST and ALT [18]. Zimmerman et al. reported that the CCl4 increase the serum ALT and AST level by the mechanism of the membrane and mitochondrial damage [19]. The present study demonstrates that TSF administration attenuates oxidative stress, decreased inflammatory cell infiltration and fibrosis in liver treated with $\mathrm{CCl}_{4}$ evidenced by complete reversal of hepatic serum biomarkers, this indicate TSF have a strong membrane stabilizing activity so it prevent the leakage of intracellular enzyme to serum and also TSF possibly have to rejuvenate the hepatocyte and healing of liver parenchyma. The level of serum bilirubin may be found in hepatitis, hepatocellular damage and hemolytic jaundice [20]. $\mathrm{CCl}_{4}$ because extensively hepatocellular degeneration and blockage of a bile duct resulted in an increased total bilirubin level.

The TSF treatment group had a significant decrease in total bilirubin level compared to untreated groups. Another marker for liver cell damage ALP (synthesized in the hepatocyte canalicular membrane) was found to be elevated in $\mathrm{CCl}_{4}$ induced liver fibrosis [21]. Serum ALP activity acts as a sensitive indicator of obstructive and space occupying lesion in the liver. This elevation is significantly suppressed by the supplementation of traditional formulation which reveals TSF have a membrane remodelling activity and clear the obstruction in hepatic biliary track, which will result if the ALP activity is decreased. Total protein and albumin produced by liver cell were decreased in $\mathrm{CCl}_{4}$ intoxicated rats. This clearly indicates an impaired synthesis of the liver cell due to liver injury [22]. The TSF treated rats showed an increase in total protein and albumin level in serum which indicates a recovery of liver damage. Hydroxyproline 
content in liver tissue is increased in $\mathrm{CCl}_{4}$ group due to excessive collagen deposition because scar formation disrupts architectural changes in the liver. Collagen is a sensitive indicator which reflects the stage of fibrosis in fibrous liver [23]. Our Masson trichrome staining results indicate TSF treated group significantly decreased the collagen content level in liver tissue. This reveals TSF has a strong anti-fibrotic activity and capacity to inhibit collagen deposition and degradation compared to $\mathrm{CCl}_{4}$ induced group. In addition, above biochemical changes in liver function correlate with the histopathological changes observed from the microscopic examination of TSF treated rats. Lymphocyte infiltration in the portal areas, hepatocyte feathery degenerative changes in both portal track and central vein region were found in $\mathrm{CCl}_{4}$ intoxicated rats. These histopathological changes were reversed to normal architecture by TSF treated rats. Hence our TSF is found to be a potent drug to treat liver fibrosis.

\section{CONCLUSION}

In conclusion, we showed that TSF significantly inhibited $\mathrm{CCl}_{4}$ induced hepatic fibrosis, and its anti-fibrotic activity may be associated due to the spectrum of synergistically active phytochemicals. This natural Siddha formulation could be developed as a promising effective therapeutic drug for liver fibrosis. However, further analytical studies may be required to support the above conclusion.

\section{CONFLICTS OF INTERESTS}

All authors have none to declare

\section{REFERENCES}

1. Friedman SL. Hepatic stellate cells: protean, multifunctional, and enigmatic cells of the liver. Physiol Rev 2008;88:125-72.

2. Gines P, Cardenas A, Arroyo V, Rodes J. Management of cirrhosis and ascites. N Engl J Med 2004;350:1646-54.

3. Friedman SL. Liver fibrosis-from bench to bedside. J Hepatol 2003;38:S38-53.

4. UE Lee, SL Friedman. Mechanisms of hepatic fibrogenesis. Best Practice Res Clin Gastroenterol 2011;25:195-206.

5. Weiler-Normann C, Herkel J, Lohse AW. Mouse models of liver fibrosis. Z Gastroenterol 2007;45:43-50.

6. Hamdy N, El-Demerdash E. New therapeutic aspect for carvedilol: antifibrotic effects of carvedilol in chronic carbon tetrachlorideinduced liver damage. Toxicol Appl Pharmacol 2012;261:292-9.

7. Shi J, Aisaki K, Ikawa Y, Wake K. Evidence of hepatocyte apoptosis in rat liver after the administration of carbon tetrachloride. Am J Pathol 1998;153:515-25.

8. Maling HM, Eichelbaum FM, Saul W, Sipes IG, Brown EA, Gillette JR. Nature of the protection against carbon tetrachloride-induced hepatotoxicity produced by pretreatment with dibenamine [N-(2-chloroethyl)
[ dibenzylamine]. Biochem Pharmacol 1974;23:1479-91.

9. Valko M, Rhodes CJ, Moncol J, Izakovic M, Mazur M. Free radicals, metals and antioxidants in oxidative stress-induced cancer. Mini-review. Chem Biol Interact 2006;160:1-40.
10. Abdelaziz DHA, Ali SA. The protective effect of Phoenix dactylifera $L$. seeds against CCl4-induced hepatotoxicity in rats. J Ethnopharmacol 2014;155:736-43.

11. Halliwell B, Gutteridge JMC. Free radicals in biology and medicine. 3rd edition. Oxford, UK: Clarendon Press; 1999.

12. Beckman $\mathrm{KB}$, Ames $\mathrm{BN}$. The free radical theory of aging matures. Physiol Rev 1998;78:547-81.

13. Mutheeswaran S, Pandikumar P, Chellappandian M, Ignacimuthu S, Duraipandiyan V, Logamanian M. Consensus analysis of sastric formulations used by non-institutionally trained siddha medical practitioners of Vir-udhunagar and Tirunelveli districts of Tamil Nadu, India. J Ethnopharmacol 2014;153:290-6.

14. Sri kamatchi priya Ramamoorthy, Diwakar Manickam, Samu subramaniam, Shyama Subramaniam. Standardisation and phytochemical screening of traditional formulation. Int J Curr Pharm Res 2017;9:70-4.

15. Vaidya Ratnam KS, Murugesa Mudaliar. Gunapadam. $1^{\text {st }}$ edition. (Siddha Materia Medica); 1936. p. 229, 345, 459, 520, 720.

16. Guo-Yu Li, Hong-Ying Gao, Jian Huang, Jin Lu, Jing-Kai Gu, et al. Hepatoprotective effect of Cichorium intybus $L$, a traditional Uighur medicine, against carbon tetrachloride-induced hepatic fibrosis in rats. World J Gastroenterol 2014;20:4753-60.

17. Fiorucci S, Antonelli E, Distrutti E, Severino B, Fiorentina R, Baldoni $\mathrm{M}$, et al. PAR1 antagonism protects against experimental liver fibrosis. Role of proteinase receptors in stellate cell activation. Hepatology 2004;39:365-75.

18. Shahjahan M, Sabitha KE, Jainu M, Shyamala Devi CS. Effect of Solanum trilobatum against carbon tetrachloride induced hepatic damage in albino rats. Indian J Med Res 2004;120:194-8.

19. Zimmerman HJ, Kodera Y, West M. Effects of carbon tetrachloride. Poisoning on the plasma levels of cytoplasmic and mitochondrial enzymes in animals with nutritional fatty metamorphosis. J Lab Clin Med 1965;66:324-33.

20. Murray RK. Porphyrins and bile pigments. In: Murry RK, Granner DK, Mayes PA, Rodwell VW. editors. Harper's illustrated biochemistry. 26th Ed. New York: McGraw-Hill Inc; 2003. p. 27085.

21. Khan AA, Alzohairy M. Hepatoprotective effects of camel milk agains CCL4-induced hepatotoxicity in Rats. Asian J Biochem 2011;6:171-80.

22. Smyth R, Munday MR, York MJ, Clarke CJ, Dare T, Turton JA. Comprehensive Characterization of serum clinical chemistry parameters and the identification of urinary superoxide dismutase in a carbon tetrachloride-induced model of hepatic fibrosis in the female Hanover Wistar rat. Int J Exp Pathol 2007;88:361-76.

23. Wang $Y$, Cheng $M$, Zhang $B$, Nie $F$, Jiang $H$. Dietary supplementation of blueberry juice enhances hepatic expression of metallothionein and attenuates liver fibrosis in rats. PLoS One 2013;8:e58659.

\section{How to cite this article}

- Diwakar Manickam, Sri Kamatchi Priya Ramamoorthy, B. Santhosh Kumar, Samu Subramaniam, Shyama Subramaniam. Biochemical and histopathological changes of traditional Siddha formulation on $\mathrm{CCL}_{4}$ induced liver fibrosis in rats. Int J Pharm Pharm Sci 2017;9(7):120-123. 